\title{
Hypernatremic Dehydration
}

National Cancer Institute

\section{Source}

National Cancer Institute. Hypernatremic Dehydration. NCI Thesaurus. Code C101229.

Dehydration resulting from abnormally high levels of sodium in the blood. Infants and individuals that are intubated are at highest risk. 